\title{
Mechanical properties of submicron oxide layers formed on a nickel-based superalloy
}

\author{
Joris EVERAERTS ${ }^{1}$, Enrico SALVATI' ${ }^{1}$, Hangyue $\mathrm{LI}^{2}$, Wei $\mathrm{LI}^{3}$, Alexander
} M. KORSUNSKY ${ }^{1}$

${ }^{1}$ Department of Engineering Science, University of Oxford, Oxford OX1 3PJ, UK

2 School of Metallurgy and Materials, University of Birmingham, Birmingham B15 2TT, UK

${ }^{3}$ Rolls-Royce plc, Elton Road, Derby DE24 8ED, UK

\section{Corresponding author:}

Dr. ir. Joris Everaerts

joris.everaerts@epfl.ch

Tel. +41216936819

Present affiliation/address: Mechanical Metallurgy Laboratory, École Polytechnique Fédérale de Lausanne, Station 12, CH-1015 Lausanne, Switzerland

\section{E-mail addresses of other authors:}

enrico.salvati@eng.ox.ac.uk; H.Y.LI.1@bham.ac.uk; wei.li@rolls-royce.com; alexander.korsunsky@eng.ox.ac.uk 


\begin{abstract}
Nickel-based superalloys are frequently used under operating conditions that lead to the formation of an oxide layer. In this study, the mechanical properties of such a submicron oxide scale formed on a nickel-based superalloy were evaluated. The Poisson's ratio and Young's modulus of the layered oxide structure were determined to be respectively 0.29 , and $259 \mathrm{GPa}$. Depth-resolved residual stress profiling with nanoscale resolution showed the presence of large compressive residual stresses up to $3000 \mathrm{MPa}$ in the oxide, with magnitude correlated to the oxide scale thickness. The relevance of the results to the crack initiation and growth behaviour is discussed.
\end{abstract}

Keywords: (A) Nickel; (A) Superalloys; (B) FIB-DIC; (C) Oxidation; (C) Residual stress 


\section{Introduction}

Nickel-based superalloys are commonly used for high-temperature structural components, such as turbine discs in gas turbine engines, due to their remarkable mechanical properties at the required operating temperatures. This includes good static properties, i.e. yield stress and ultimate tensile strength, and in particular high resistance to creep deformation. Furthermore, these alloys also show good corrosion resistance when exposed to oxidising environments at high temperatures, and good resistance to fatigue crack initiation and growth during cyclic loading [1]. In fact, turbine discs are required to withstand a combination of static, cyclic and sustained static loads [2]. The combination of cyclic and sustained loading, commonly referred to as dwell fatigue, is particularly crucial, and involves fatigue with a dwell or hold time at the maximum load. Resistance to dwell fatigue crack growth is a key requirement for nickel-based superalloys in turbine disc applications, and understanding how to increase this resistance is challenging because it is governed by several interacting mechanisms [3].

Firstly, the exposure to elevated temperature and dwell loads leads to crack tip blunting as well as creep in the region ahead of the crack tip, which causes stress relaxation and consequently a reduced crack growth rate [4]. On the other hand, creep damage such as the formation of voids at grain boundaries can also lead to a higher crack growth rate [5]. Secondly, the oxidising environment leads to intergranular oxygen diffusion ahead of the crack tip, causing grain boundary decohesion (i.e. dynamic embrittlement) [6]. Furthermore, an oxide layer is formed along the crack wake and at the crack tip. This mechanism, which is generally referred to as stressassisted grain boundary oxidation (SAGBO) [7-10], results in phase transformation stresses, i.e. oxide growth stresses, and a lowered intrinsic fracture toughness at the crack tip due to the brittle nature of the oxides $[11,12]$. The fundamental complexity of the high temperature dwell fatigue behaviour of nickel-based superalloys lies in the synergy between 'mechanical' phenomena, i.e. the stress and deformation fields ahead of the crack tip and local mechanical properties, and 'environmental' phenomena, i.e. oxygen diffusion and oxide formation at the crack tip. For example, the presence of tensile stresses tends to facilitate oxygen diffusion [13] and consequently promotes the formation of various oxides, which in turn changes the local stress field $[13,14]$. 
The influence of the environment on dwell fatigue crack growth rates in nickel-based superalloys has been shown to be substantial [14,15], which is why oxide formation has been studied extensively. However, these studies generally only focus on the thermodynamic aspect of oxidation, which is complex due to the fact that nickel-based superalloys often contain more than ten alloying elements [1]. The resulting oxide structure is layered in a thermodynamic sequence that is governed by the stability of the various oxides, the local oxygen partial pressure required for oxide formation, and diffusion properties of various metal ions and oxygen. This layered structure evidently depends on the precise alloy composition, but typically consists of rapidly forming oxides such as $\mathrm{NiO}$ and $\mathrm{CoO}$ close to the surface, followed by a $\mathrm{Cr}_{2} \mathrm{O}_{3}$ layer that to some extent acts as a diffusion barrier, and finally $\mathrm{TiO}_{2}$ particles and finger-like $\mathrm{Al}_{2} \mathrm{O}_{3}$ intrusions closest to the metal matrix. Additionally, $\mathrm{TiO}_{2}$ particles are sometimes found to be present in the $\mathrm{Cr}_{2} \mathrm{O}_{3}$ layer, and in some cases more complex oxides such as $\left(\mathrm{Ni}_{1}\right.$ $\left.{ }_{x} \mathrm{Co}_{x}\right) \mathrm{O}, \mathrm{NiCr}_{2} \mathrm{O}_{4}$ or $\mathrm{MnCr}_{2} \mathrm{O}_{4}$ have been observed [3,7,16-19].

On the other hand, the mechanical aspects of oxide formation are less well understood. Micromechanical modelling has shown the importance of phase transformation strain, which induces a residual stress field. For most oxides in nickelbased superalloys, the transformation strains are positive (expansive) and thus lead to compressive stresses, although the magnitude depends on the type of oxide and the reactant phases. In the case of surface oxidation, these compressive stresses can become high enough to cause buckling and spallation [20]. In the case of crack tip oxidation, it has been proposed that these compressive residual stresses lead to crack-tip shielding [21,22]. In contrast, a self-consistent mathematical model developed by Cimbaro et al. suggests that a wedge-shaped oxide intrusion is always anti-shielding and leads to an increased local tensile stress at the crack tip, the magnitude of which depends on the length of both the crack and the intrusion [11]. These models generally assume a simplified morphology containing only one oxide species. Furthermore, the width of the oxide intrusion close to the crack tip is reportedly only 20-60 $\mathrm{nm}$ [19], which explains the lack of experimental verification of these mechanical phenomena.

Oxide formation in nickel-based superalloys does not only affect crack propagation, but also crack initiation. In the very high cycle fatigue regime, the initiation stage may account for over $90 \%$ of the total fatigue life [23], which means that changes in crack 
nucleation behaviour have a drastic impact on fatigue behaviour. In this regime the crack initiation location tends to shift from surface to subsurface regions, i.e. from surface defects to intrinsic microstructural features [24]. However, a study by Cruchley et al. [25] showed that the formation of a surface oxide layer promoted crack initiation at the surface and consequently led to a reduced fatigue life in most cases. In some cases, i.e. at certain applied stress levels, surface oxidation had a small beneficial effect on the fatigue life because it altered the microstructure underneath the oxide. In addition, the formation of residual stresses due to the volume expansion associated with oxide growth is also expected to affect crack initiation. This illustrates that the effect of surface oxidation on crack initiation is complex.

The purpose of this study is to investigate the mechanical properties of a naturally grown oxide layer with submicron thickness on the surface of a nickel-based superalloy, in order to understand better the mechanical behaviour of this complex layered structure. The layer morphology, Young's modulus, Poisson's ratio and depthresolved residual stress variation are evaluated. The applicability of the results to the specific case of crack initiation is discussed, as well as the potential issues in transferring the results to crack tip oxidation phenomena during dwell fatigue crack growth.

\section{Materials and methods}

A rectangular block of approximately $20 \times 10 \times 5 \mathrm{~mm}$ was cut by electro-discharge machining from RR1000 alloy. The nominal composition of this alloy in wt.\% is 52.3 Ni, 18.5 Co, 15 Cr, 5 Mo, 3.6 Ti, 3 Al, 2 Ta, 0.5 Hf, 0.06 Zr, 0.027 C and 0.015 B [26]. All the surfaces were ground on wet SiC paper and polished using $6 \mu \mathrm{m}$ diamond paste to remove the damage from the EDM process and to produce a surface finish, $\mathrm{R}_{\mathrm{a}}$, of approximately $0.4 \mu \mathrm{m}$. All edges and corners were chamfered to reduce stress concentrators and polished to the same surface finish. The sample was then oxidised in air at $650{ }^{\circ} \mathrm{C}$ for 4000 hours [17]. Scanning electron microscope (SEM) imaging and focused ion beam (FIB) milling were performed at the Multi-Beam Laboratory for Engineering Microscopy (MBLEM) in Oxford, using a TESCAN LYRA3 dual beam system equipped with an Oxford Instruments $X-M^{N}{ }^{N}$ detector for energy-dispersive X-ray (EDX) analysis. 


\subsection{Poisson's ratio}

Poisson's ratio was determined based on the two-stage four-slot 'focused ion beam digital image correlation' (FIB-DIC) milling method described by Sebastiani et al. [27]. In this experiment, which assumes the stress state to be equibiaxial, firstly two horizontal trenches of length $20 \mu \mathrm{m}$ and width $0.5 \mu \mathrm{m}$, with a distance of $2 \mu \mathrm{m}$, were FIB milled in the surface in 25 steps of $75 \mathrm{~nm}$. This allowed for full stress relief in the vertical direction of the wall created in between both trenches. At the second stage, two vertical trenches of length $2 \mu \mathrm{m}$ and width $0.5 \mu \mathrm{m}$ were milled, forming a central rectangular island of 2 by $2 \mu \mathrm{m}$ which was fully stress relieved in both the vertical and horizontal direction. Open source digital image correlation (DIC) software [28] was used to track the strain relief of this island during both stages. The relief strain values in the vertical direction after the first and second stage were used to determine Poisson's ratio.

\subsection{Young's modulus}

A micro-cantilever was manufactured by FIB milling and subjected to in situ bending using an Alemnis Nanoindenter with a diamond cube corner tip (Synton-MDP) in displacement control with a constant tip speed of $50 \mathrm{~nm} / \mathrm{s}$. A 3D linear elastic finite element model was constructed in order to interpret the load-displacement data, using C3D8R and C3D6 elements for oxide and substrate, respectively. The nanoindenter tip was represented as a vertical point load. Young's modulus and Poisson's ratio of the substrate were fixed at $210 \mathrm{GPa}$ and 0.3 , respectively [29]. For the oxide, the Poisson's ratio value was taken from the four-slot FIB-DIC experiment and Young's modulus was set as a variable, which allowed its determination by fitting the model response to the load-displacement data.

\subsection{Residual stress}

Depth-resolved residual stress profiles were obtained using the ring-core 'focused ion beam - digital image correlation' (FIB-DIC) technique [30]. This involves incremental FIB milling of a circular trench, thereby creating a cylindrical micropillar that is gradually being relieved from residual stress. DIC on the patterned top surface of the pillar allows for determining the strain relief after each incremental milling step, which captures information on in-depth residual stress variation. The depth-resolved residual stress profile can then be reconstructed using the eigenstrain-based non-integral 
method, as fully described elsewhere [31,32]. In the current study, four ring-core FIBDIC experiments with pillar diameter $10 \mu \mathrm{m}$ were performed at random locations on the sample surface. The FIB voltage and current were fixed throughout each experiment, and the resulting incremental FIB milling step was determined to be 70 $\mathrm{nm}$ in the oxide and $125 \mathrm{~nm}$ in the substrate. Residual stress profiles were obtained for a depth range between $0.25 \mu \mathrm{m}$ and $2.5 \mu \mathrm{m}$, or equivalently $0.025 \%$ and $0.25 \%$ of the pillar diameter, which is based on the sensitivity of the non-integral method [32]. Young's modulus and Poisson's ratio, which are needed in order to obtain residual stress from the relief strain as measured by DIC, were taken to be respectively 210 GPa and 0.3 for the substrate [1]. For the oxide, both parameters were experimentally evaluated in the current study (see section 3.2 below). The residual stress evaluation was based on the assumption of in-plane equibiaxial stress, supported by the fact that the measured relief strain values in the horizontal and vertical direction were in close agreement for each experiment. Consequently, the average values were used for residual stress evaluation. The error bars, which represent a 95\% confidence interval, take into account the difference in relief strain value between the horizontal and vertical direction, the uncertainty in exact milling depth (based on multiple measurements from SEM images), the error as a result of DIC analysis and the uncertainty due to elastic anisotropy effects in the substrate [33,34]. After each experiment was completed, a cross-section of the pillar was made by FIB milling in order to examine the local thickness of the oxide layer.

\section{Results}

\subsection{Morphology}

The surface morphology of the oxide layer is illustrated in Figure 1, which shows SEM images of the sample surface at two different locations. The presence of nanocrystalline oxide particles can be observed in Figure 1a, in some cases with planar crystal facets. This figure also shows needle-shaped oxides of varying thickness and length, which tend to be clustered in islands. A large number of such oxide nano-whiskers with high aspect ratio can be seen in Figure 1b. EDX analysis of the needles revealed the presence of mainly $\mathrm{Ti}$ and $\mathrm{O}$ and, to a lesser extent, $\mathrm{Cr}$. Similar oxide particles and needle-like oxides have been reported elsewhere for alloy RR1000, and were shown to contain high levels of $\mathrm{Cr}$ and $\mathrm{Ti}$ [20]. 

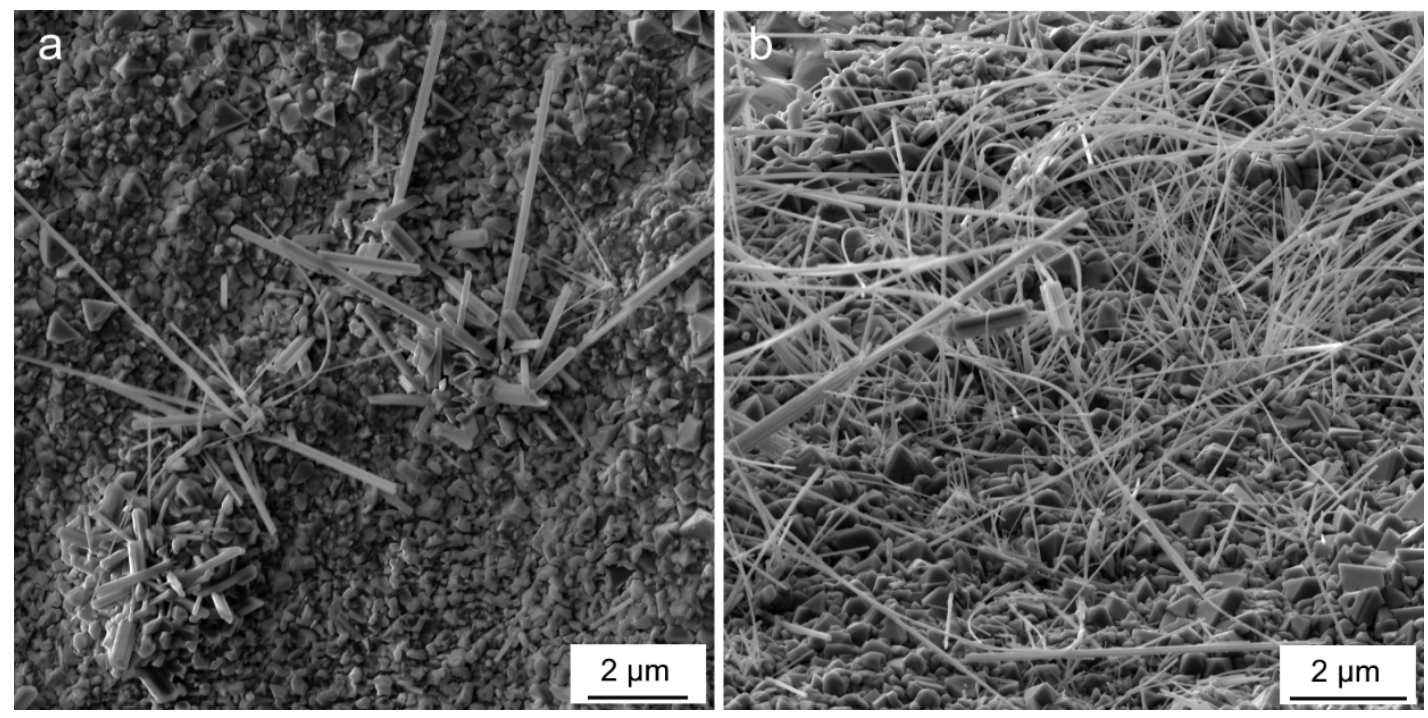

Figure 1. SEM images showing (a) oxide needle 'islands' on sample surface and (b) oxide nano-needles with various aspect ratios

Cross-sections were made by FIB milling in order to assess the thickness and subsurface morphology of the oxide layer. Figure 2a shows a typical cross-section through the oxide and the underlying substrate. The total oxide layer thickness at this particular location is approximately $700 \mathrm{~nm}$, and more generally ranged between 600 and $900 \mathrm{~nm}$. However, at certain locations the oxide layer thickness was found to be larger. For example, Figure $2 \mathrm{~b}$ shows a cross-section through a cluster of oxide needles, with a local maximum oxide layer thickness of approximately $1.8 \mu \mathrm{m}$. In general, the observed morphology consists of either nanocrystalline particles or needles at the surface (I), below which there is a relatively thick layer (II), a thin layer with darker contrast (III) and finally the metal substrate with finger-like oxide intrusions (IV). In some cases, e.g. Figure $2 b$, these intrusions were observed to penetrate up to a depth of approximately $4 \mu \mathrm{m}$ into the substrate. These SEM images also suggest the possible presence of voids in the substrate close to the oxide interface, e.g. Figure 2a. However, it has been reported that void-like artefacts can be produced by FIB preparation and SEM imaging, and that these features may in fact be internal oxides [35]. 


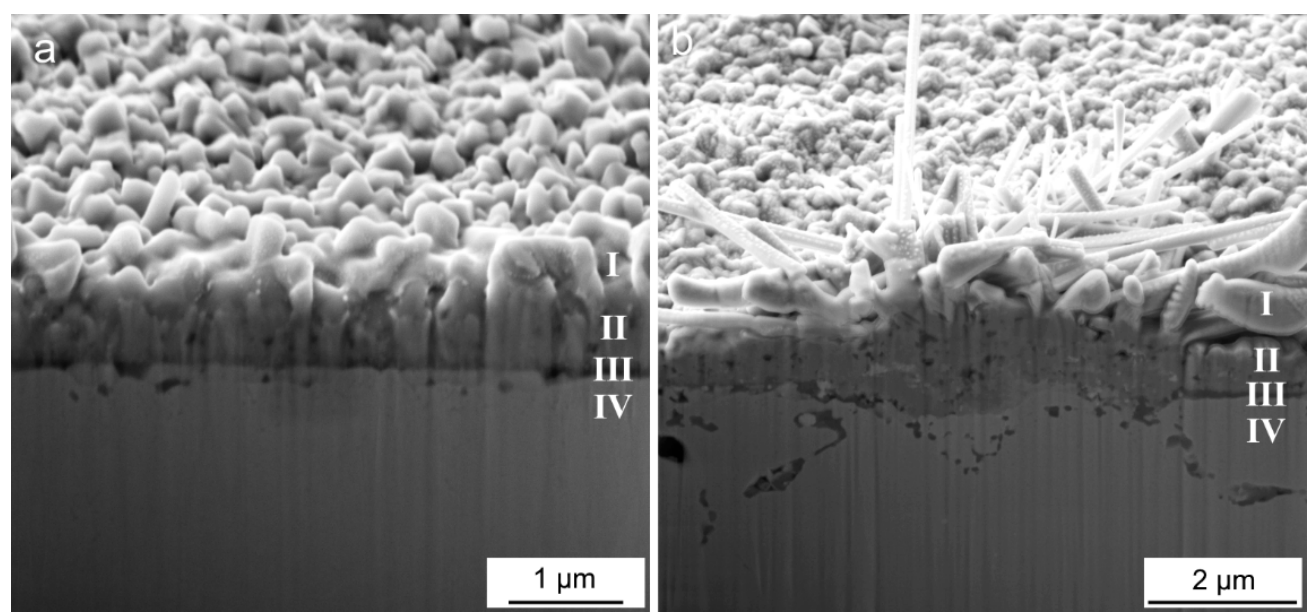

Figure 2. SEM backscattered electron images of FIB milled cross-sections through the oxide layer at (a) a random location and (b) an oxide needle 'island' (sample tilted at $55^{\circ}$ with respect to horizontal axis)

A qualitative assessment of the chemical composition of the oxide layer was performed via EDX analysis on a FIB milled cross-section. Figure 3 shows an SEM image of the examined cross-section and element maps for $\mathrm{Ni}, \mathrm{Co}, \mathrm{Al}, \mathrm{Ti}$ and $\mathrm{Cr}$. It should be noted that the maps of other detected minor elements, such as $\mathrm{O}$ and $\mathrm{Fe}$, were omitted. The EDX results show that the top layer (I) contains a higher concentration of $\mathrm{Ti}$ and $\mathrm{Cr}$. The $\mathrm{Cr}$ content is still high in the underlying thicker layer (II), whereas the thin layer underneath (III) and the intrusions (IV) contain mainly Al. The concentration of $\mathrm{Ni}$ and $\mathrm{Co}$ appears to be more homogeneous, with the exception of the Al-containing layer (III) and intrusions (IV) in which it is lower. These observations are in agreement with a previous study on the same RR1000 alloy [17], which reports that the outer surface contains rutile $\left(\mathrm{TiO}_{2}\right)$ crystals, with an underlying chromia layer and subsurface alumina. Furthermore, these phases may incorporate other elements in solid solution. For example, the chromia layer (II) is also known to contain dissolved titanium. 


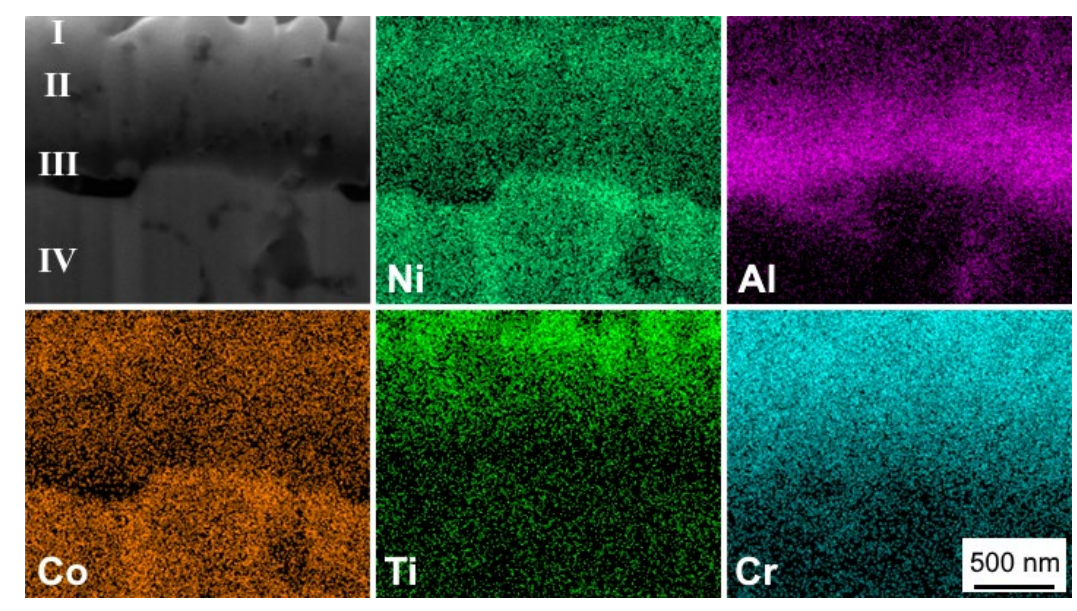

Figure 3. SEM image and EDX element maps of FIB-milled cross-section through oxide layer and underlying substrate

\subsection{Mechanical properties}

A two-stage four-slot FIB-DIC experiment was used to determine Poisson's ratio of the oxide scale [27]. To the author's knowledge, this technique has never before been applied successfully to a submicron native oxide layer. The results of this experiment are presented in Figure 4. In stage I, two horizontal slots are FIB milled in a stepwise fashion, allowing full residual stress relief in the vertical $(y)$ direction while the material is still constrained in the horizontal $(x)$ direction. Next, in stage II two vertical slots are FIB milled to create a square island, which is thus fully relieved of residual stress in both $x$ and $y$ directions. The total strain relief in the $y$ direction after the second stage $\Delta \varepsilon_{y}^{I I}$ is different from the strain relief in $y$ after the first stage $\Delta \varepsilon_{y}^{I}$ due to the Poisson effect, as can be observed from Figure 4 . Therefore, Poisson's ratio $v$ can be calculated from this experiment as [27]:

$$
v=\frac{\Delta \varepsilon_{y}^{I}}{\Delta \varepsilon_{y}^{I I}}-1
$$

Using this formula, Poisson's ratio of the oxide scale was found to be approximately equal to 0.29 . It can also be observed from Figure 4 that after the last milling step the relief strain in $x\left(\varepsilon_{x}\right)$ is approximately equal to the relief strain in $y\left(\varepsilon_{y}\right)$. Moreover, both $\varepsilon_{x}$ and $\varepsilon_{y}$ have reached a plateau during the last five milling steps. This confirms that the residual stress in the oxide layer was equibiaxial, and that this stress was fully relieved in the central rectangular island after the two-stage four-slot FIB-DIC experiment. 


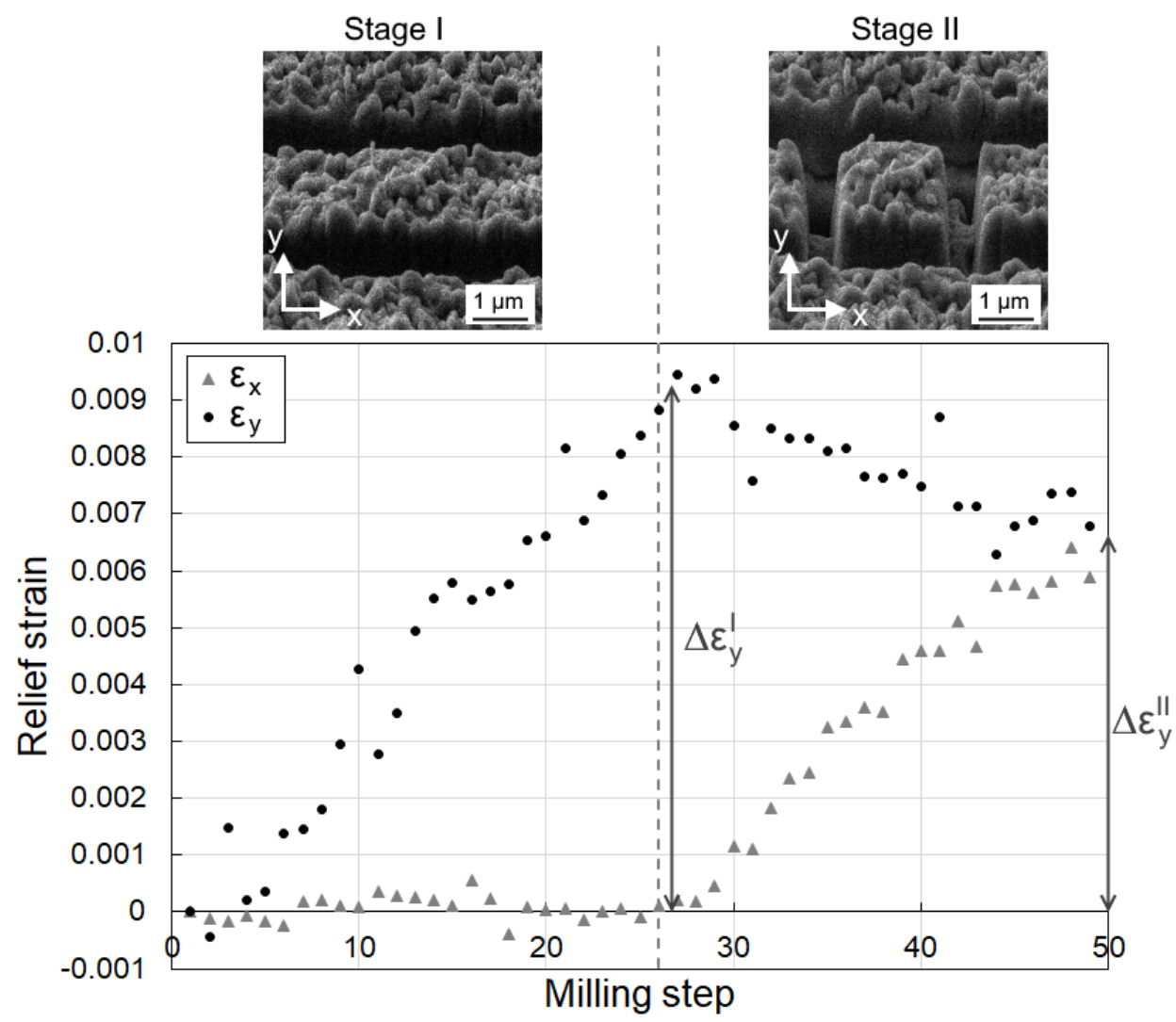

Figure 4. Relief strain in $x\left(\varepsilon_{x}\right)$ and $y\left(\varepsilon_{y}\right)$ as a function of milling step obtained from two-stage four-slot FIB-DIC experiment to determine Poisson's ratio of oxide layer

A micro-cantilever was produced by FIB milling and subjected to in situ bending by means of a nanoindenter in order to obtain Young's modulus of the oxide layer. Figure 5 a shows an SEM image of the side view of the cantilever and the nanoindenter tip during the early stages of the bending test. In Figure $5 b$, an SEM image of the front view of the cantilever prior to the bending test is presented, showing the morphology of the cantilever cross-section. It can be observed that the cross-section consists of an upper rectangular part, which contains the oxide layer, and a lower triangular part, containing the substrate. The triangular part forms angles of 70 degrees with respect to the sample surface. This geometry is a result of the constraints of the SEM-FIB dual beam system, in which the FIB column is positioned at 55 degrees and the sample stage allows for maximum 15 degrees negative tilt. Figure $5 \mathrm{c}$ shows a schematic drawing of the cantilever, including the dimensions that were measured from SEM images and the position of the nanoindenter tip (white arrow). 

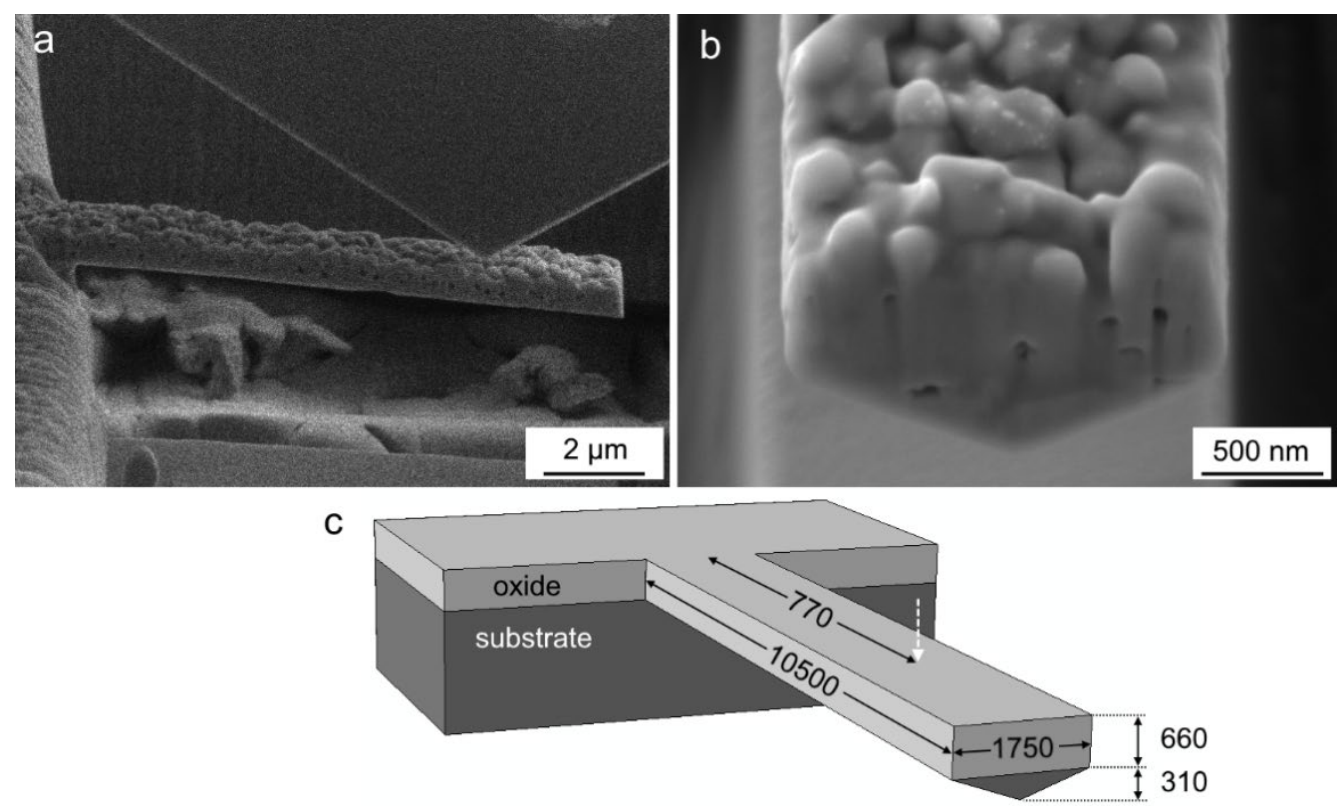

Figure 5. SEM images of FIB milled cantilever, showing (a) side view during bending test and (b) front view prior to test (sample tilted at $55^{\circ}$ with respect to horizontal axis); (c) Model for FE simulation (dimensions in $\mathrm{nm}$ )

The results of the cantilever bending test are shown in Figure 6 in the form of load versus displacement data for the nanoindenter tip. There is a linear elastic regime up to a maximum load of approximately $0.075 \times 10^{-3} \mathrm{~N}$ and displacement of around 800 $\mathrm{nm}$. At this point, a crack propagated through the oxide layer and the load dropped to a value of roughly $0.04 \times 10^{-3} \mathrm{~N}$. The load did not drop to zero because the crack arrested at the interface between oxide and substrate, which means that the fracture did not cause separation of the cantilever from the sample. This can be observed in Figure 7, which shows an SEM image of the cantilever after the bending test. In order to interpret the load-displacement data in the linear elastic regime, a finite element (FE) model was used to simulate the bending test, as shown in Figure $5 \mathrm{c}$. The oxide scale in the model is assumed to be homogeneous, which will be discussed further below. By fitting of the model response to the load-displacement data, the Young's modulus of the oxide layer was determined to be $259 \mathrm{GPa}$. Additionally, it is important to consider possible errors due to the accuracy in cantilever dimensions. The height of the cantilever cross-section is particularly crucial, given the fact that the area moment of inertia depends on the height to the power of three. Because of the edge effect in SEM images, the dimensional uncertainty can be estimated as approximately $\pm 20 \mathrm{~nm}$ [36]. A height variation of $\pm 20 \mathrm{~nm}$ was therefore implemented in the FE model, 
and it was found that this results in a relative error on Young's modulus of approximately $\pm 12 \%$.

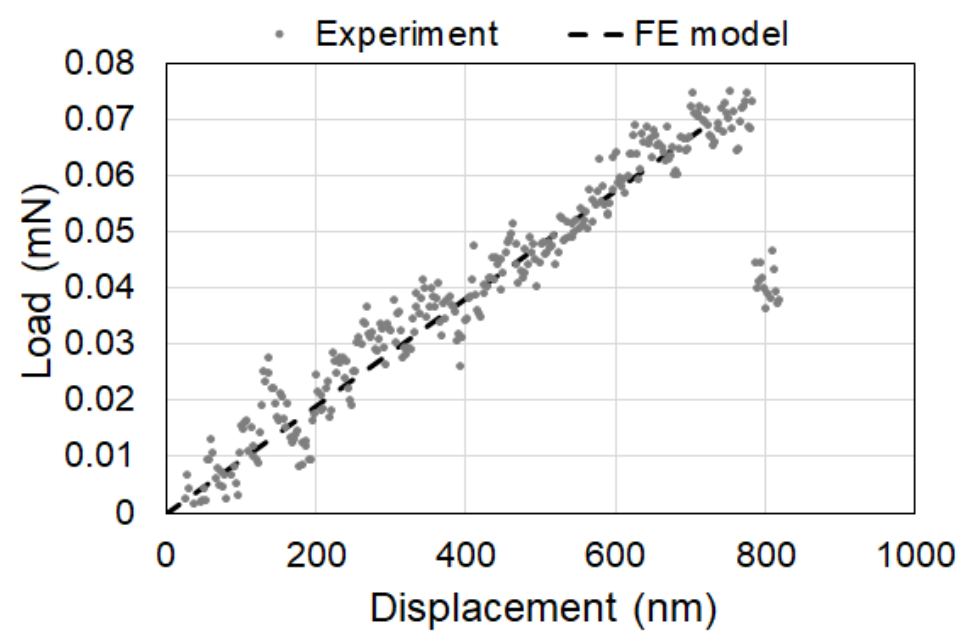

Figure 6. Load $(\mathrm{mN})$ versus displacement $(\mathrm{nm})$ for cantilever bending test, showing experimental data and FE model after optimisation

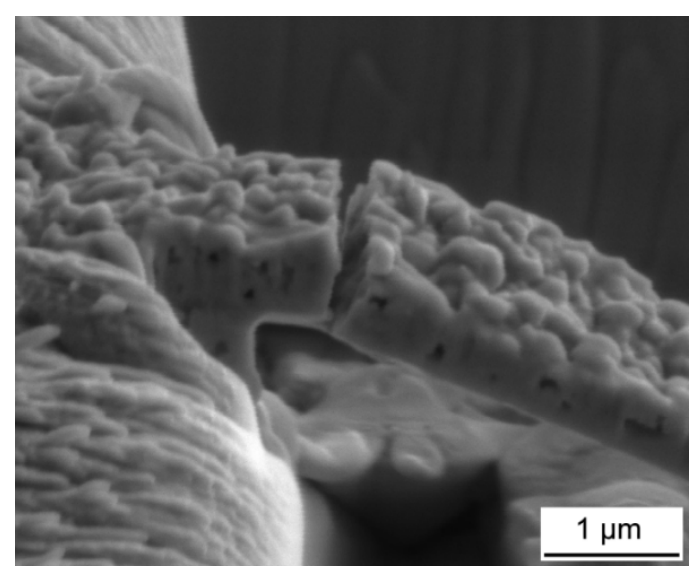

Figure 7. SEM image of cantilever after bending experiment, showing fracture of the oxide layer near the base of the cantilever

The depth-resolved in-plane residual stress near the surface was evaluated by means of ring-core FIB-DIC and the non-integral method [32]. Note that the assumed stress state is equibiaxial, as confirmed by the two-stage four-slot FIB-DIC experiment described above (Figure 4). The obtained residual stress profiles as a function of depth are shown in Figure 8 for each of the four probed locations ( $a, b, c \& d)$. SEM images of cross-sections of the surface at each location are also shown in Figure 8a, b, c and d. The dashed vertical lines in the plot represent the local oxide thickness, i.e. the interface between the oxide layer and the substrate, as measured from the SEM images. In general, the shape of the residual stress profiles is similar at all four analysed locations, with a maximum compressive stress peak located in the oxide 
layer close to the interface. By comparing the profiles and cross-sections at locations $a \& b$ with those at locations $c \& d$, it can be observed that magnitude of residual stress appears to be related to the thickness of the oxide layer. At locations a \& b, the thickness of the oxide is circa $650-680 \mathrm{~nm}$ and the residual stress reaches values of 1600-1800 MPa in compression. On the other hand, at locations $c \& d$, the oxide thickness is approximately $840-860 \mathrm{~nm}$ and the maximum residual stress is in the range of $2400-3000 \mathrm{MPa}$ in compression. The depth at which the maximum residual stress peak occurs also shifts corresponding to the thickness of the oxide layer. Additionally, it can be observed that there is a sharp decline in residual stress in the substrate, although the stress remains compressive up to a depth of at least $2.5 \mu \mathrm{m}$. To the author's knowledge, these experiments provide the first direct measurement of depth-resolved residual stress in a submicron oxide layer.

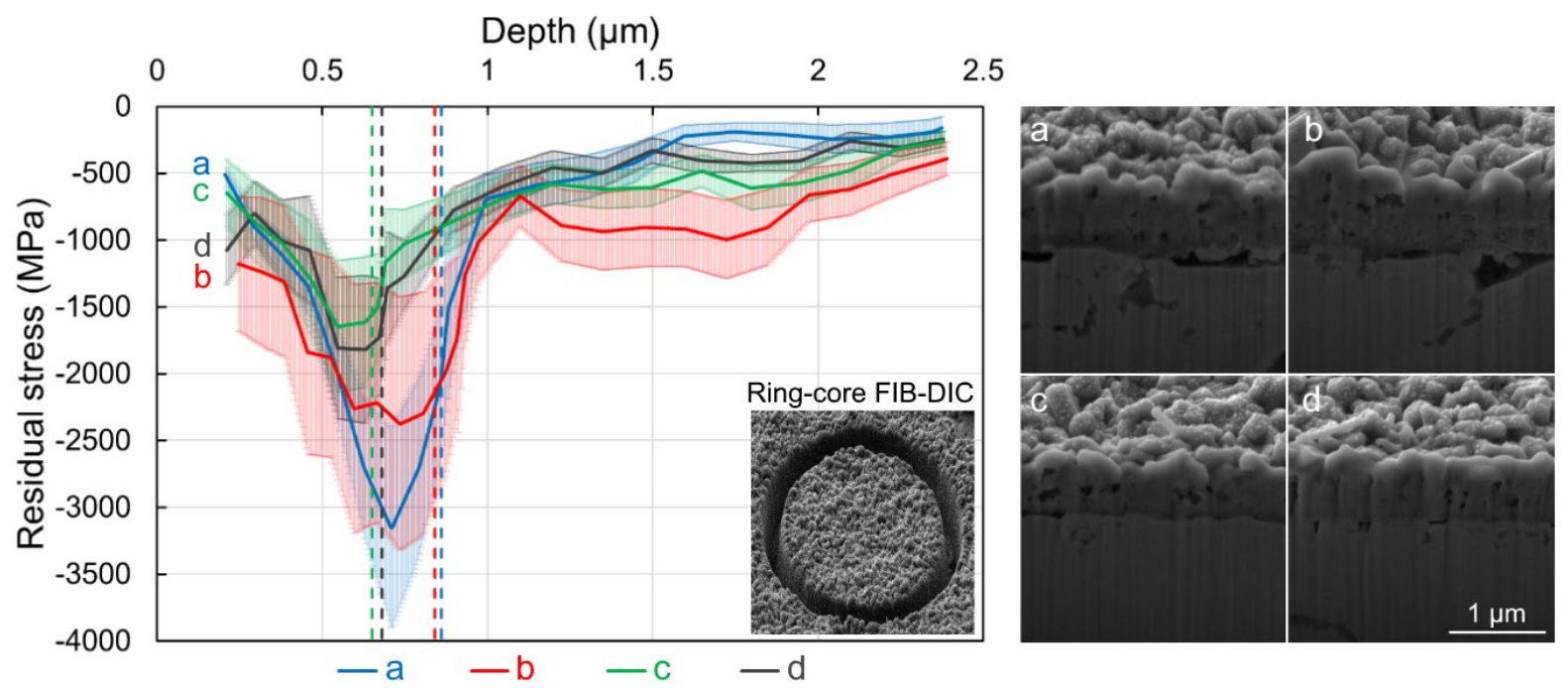

Figure 8. Residual stress (MPa) as a function of surface depth ( $\mu \mathrm{m})$ at four locations $(a, b, c$ $\& d$ ) on the sample (error bars represent 95\% confidence interval), obtained by ring-core FIB-DIC measurements; SEM images on the right show the respective cross-sections (sample tilted at $55^{\circ}$ with respect to horizontal axis)

The residual stress in the oxide layer reaches very high values of up to $3000 \mathrm{MPa}$ in compression and can be linked to the local oxide layer thickness. Consequently, buckling failure and spallation of the oxide was observed in certain locations on the sample surface. Two examples of such failure are shown in Figure 9. In Figure 9a, the oxide layer is bulging out and has partially fractured. From Figure 9b, it can be observed that locally the oxide is relatively thick (approximately $1.6 \mu \mathrm{m}$ ), which would explain why buckling failure occurred at this specific location. Furthermore, islands of oxide needles are present in the gap between the oxide and the substrate. These 
appear to have grown both upwards from the substrate (i.e. resembling 'stalagmites') and downwards from underneath the oxide layer (i.e. resembling 'stalactites'). The growth of oxide needles in within this gap implies that the damage indeed occurred by spallation during the oxidation process, and was not caused by, for example, thermal stresses due to cooling or by sample handling afterwards.
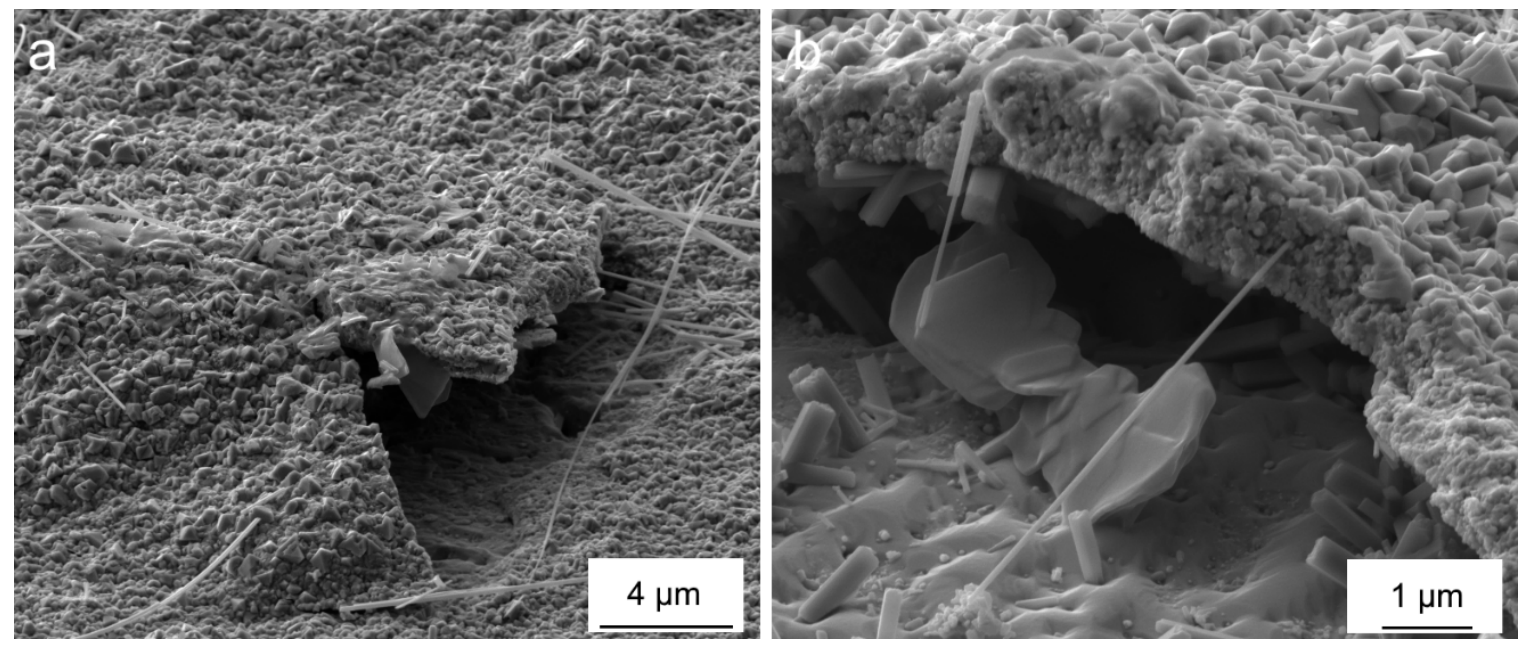

Figure 9. SEM images showing two cases of local buckling and spallation of the oxide layer (sample tilted at $55^{\circ}$ with respect to horizontal axis)

\section{Discussion}

In order to understand the mechanical properties that were measured for the oxide, the results should be interpreted within the context of the observed morphology of the oxide layer. The oxide has a complex layered structure which consists of a rough layer with nanocrystalline particles at the surface (I), followed by a relatively thick layer (II), a thin layer with darker contrast (III) and finally the metal substrate with finger-like oxide intrusions (IV), as shown in Figure 2. In terms of composition, the element maps obtained by EDX (Figure 3) confirm the thermodynamic layering sequence that has been reported in literature $[7,17]$. The outer layer $(\mathrm{I})$ contains $\mathrm{TiO}_{2}$ crystals, below which there is a thicker $\mathrm{Cr}_{2} \mathrm{O}_{3}$ layer (II), an $\mathrm{Al}_{2} \mathrm{O}_{3}$ layer (III) as well as $\mathrm{Al}_{2} \mathrm{O}_{3}$ intrusions (IV). However, the layers are not well-defined, both structurally and in terms of composition. Structurally, the thickness of each layer is inhomogeneous, e.g. the $\mathrm{Al}_{2} \mathrm{O}_{3}$ layer (III) in Figure 3, and the depth of the $\mathrm{Al}_{2} \mathrm{O}_{3}$ intrusions shows large variability. In terms of composition, the various oxide phases can contain other elements in solid solution, and sometimes mixed layers can be formed [19]. For example, the EDX results indicate the presence of $\mathrm{Ni}$ and $\mathrm{Co}$ in most layers, and it has been reported previously that the chromia layer (II) also contains titanium [17], possibly in the form 
of $\mathrm{TiO}_{2}$ particles [16]. Moreover, the current results do not exclude the possibility that more complex oxides may have formed [7].

Nonetheless, in the first instance it can be worthwhile to compare the mechanical properties that were measured for the oxide layer with those found in literature for pure oxide phases. From the two-stage four-slot FIB-DIC experiment (Figure 4), the Poisson's ratio of the oxide layer was found to be 0.29 . In comparison, the Poisson's ratio is reported to be $0.25-0.3$ for pure $\mathrm{Cr}_{2} \mathrm{O}_{3}$ [37-39], 0.26 for pure $\mathrm{Al}_{2} \mathrm{O}_{3}$ [40], 0.28 for pure $\mathrm{TiO}_{2}$ [41], 0.416 for sintered pure $\mathrm{NiO}$ [42] and 0.38 for $\mathrm{CoO}$ [43]. It is clear that the values for these oxides cover a rather broad range and, as mentioned in the previous paragraph, the possible impurity of the identified phases introduces another level of complexity, making comparison difficult. Additionally, it is important to note that the various layers will have different contributions to the total strain relief that is measured by the FIB-DIC method. This can be understood by considering that while the whole central 'island' is being incrementally relieved from residual stress during FIB milling, DIC is only performed on the top surface. This means that the deeper layers have a smaller contribution to the observed strain relief value. This sensitivity as a function of milling depth has been evaluated for a ring-core geometry in the form of an influence function, showing that the major contribution is provided by layers at depths between $1.5 \%$ and $20 \%$ of the ring-core diameter [44]. In the current case, i.e. for a rectangular 'four-slot' geometry, the exact influence function is unknown, but it can be assumed that the sensitivity is also much larger for the top layers. Therefore, it is not surprising that the obtained value for Poisson's ratio $(0.29)$ is closest to the values for $\mathrm{TiO}_{2}(0.28)$ and $\mathrm{Cr}_{2} \mathrm{O}_{3}(0.25-0.3)$, seeing as the outer layer consists of mainly $\mathrm{TiO}_{2}$ followed by a $\mathrm{Cr}_{2} \mathrm{O}_{3}$ layer.

Young's modulus of the oxide layer was evaluated by microcantilever bending and combined FE modelling, resulting in a value of approximately $259 \mathrm{GPa}$ (see Figure 5 and Figure 6). For simplicity, it was assumed in the FE model that the oxide layer is both homogeneous and smooth, as shown in Figure 5c. In comparison, Young's modulus is reported to be 234-273 $\mathrm{GPa}$ for $\mathrm{Cr}_{2} \mathrm{O}_{3}$ [37,39,45], $270.7 \mathrm{GPa}$ for $\mathrm{TiO}_{2}$ [22], 362-393 GPa for $\mathrm{Al}_{2} \mathrm{O}_{3}[22,46]$ and 230-260 GPa for $\mathrm{NiO}$ [22]. It should also be noted that the exact oxide stoichiometry has a large influence on these values $[37,47]$. Although the complex morphology of the oxide makes direct comparison difficult, the value that was measured in the current study is in the expected range, i.e. close to the 
moduli of the relevant pure oxides. In particular, the measured value (259 GPa) is closest to the literature values for pure $\mathrm{Cr}_{2} \mathrm{O}_{3}$ (234-273 GPa), which is sensible given the fact that the cantilever contains a relatively thick chromium-containing oxide layer (see layer II in Figure 3). lyer et al. [48] also used micro-cantilever bending to examine the mechanical behaviour of the oxide scale on a superalloy (Allvac 718Plus), and they reported a Young's modulus of 194-206 GPa, which is considerably lower compared to the current study. However, a different alloy composition results in the formation of different oxide species, e.g. an outer spinel phase in the case of Allvac 718Plus [48], which would evidently result in a different mechanical behaviour. Regarding the FE model, the simplification of using a smooth surface is not expected to introduce significant errors on the result, because the surface roughness is mainly composed of individual oxide particles which presumably do not contribute any structural rigidity during bending. The model could be developed further by including the individual layers instead of assuming one homogeneous oxide layer. However, as mentioned the morphology is complex and has a large variability. One possible strategy, which could be employed in future studies, would be to use FIB tomography after the micro-cantilever bending experiment in order to construct a 3D model of the cantilever. By performing a large number of tests, each coupled to an accurate bespoke FE simulation, the unknown Young's modulus of each layer could then be evaluated statistically.

The depth-resolved residual stress profiles, shown in Figure 8, reveal that a large compressive residual stress peak is present in the oxide. If the oxide layer is thicker, the magnitude of residual stress is higher and the peak shifts to a deeper position. At locations where the oxide layer grew to a relatively large thickness (circa $1.6 \mu \mathrm{m}$ ), the very high compressive residual stress caused local buckling and spallation (see Figure 9 ). The development of compressive stress during oxidation is a result of phase transformation strain, which occurs because oxide formation involves a volume increase. This can be described in the first instance by the Pilling-Bedworth ratio (PBR), which is the volumetric misfit of a metal oxide compared to its corresponding metal [49]. For example, $\mathrm{PBR}$ is equal to 1.65 for $\mathrm{NiO}$ in $\mathrm{Ni}$ [12]. However, the problem becomes more complex for alloys, because several alloying elements can be oxidised and the local composition of the alloy substrate will also change [50]. Furthermore, in nickel-based superalloys the local depletion of oxide-forming elements causes $\gamma^{\prime}$ 
precipitates in the substrate to transform to $\gamma$, forming a $y^{\prime}$ denuded layer [17]. The transformation strains of common oxide phases formed in superalloys were calculated by Chan [21]. For example, the transformation strains for the formation of $\mathrm{TiO}_{2}, \mathrm{Cr}_{2} \mathrm{O}_{3}$ and $\mathrm{Al}_{2} \mathrm{O}_{3}$ in a $\mathrm{Ni}$ phase, containing $\mathrm{Ti}, \mathrm{Cr}$ or $\mathrm{Al}$ in solid solution, are respectively 227 $\%, 596 \%$ and $519 \%$. Given these values, the presence of very large compressive growth stresses in the oxide layer is not surprising. Another interesting observation from Figure 8 is that the residual stress remains compressive in the substrate up to a depth of at least $2.5 \mu \mathrm{m}$. This cannot be explained by, for example, the presence of a $\gamma^{\prime}$ denuded layer, because for RR1000 the misfit strain between $\gamma$ ' and $\gamma$ is positive and very small at room temperature (approximately $7 \times 10^{-4}$ ) [51], which means that the lattice parameter of $\gamma^{\prime}$ is larger. However, the SEM images of cross-sections show that finger-like $\mathrm{Al}_{2} \mathrm{O}_{3}$ intrusions are present up to a maximum depth of about $4 \mu \mathrm{m}$ (Figure $8 \mathrm{a}$ and $\mathrm{b}$ ). The formation of $\mathrm{Al}_{2} \mathrm{O}_{3}$ from the $\gamma^{\prime}$ phase $\left(\mathrm{Ni}_{3} \mathrm{Al}\right.$ in the simplified case) results in a transformation strain of around $466 \%$ [21], which means that the formation of these finger-like intrusions is indeed expected to cause compressive residual stress. The surface preparation prior to oxidation could also have an influence, since it has been shown recently that polishing with diamond slurry induces compressive residual stresses up to a few micrometers in depth [52]. Additionally, the current results show for the first time that the ring-core FIB-DIC technique is capable of providing depth-resolved residual stress profiles in native oxide layers with submicron thickness.

The experimental results obtained in this study provide valuable information that can help with understanding the effect of oxidation on fatigue crack initiation. The roughness of the outer $\mathrm{TiO}_{2}$ layer as well as the higher Young's modulus of the entire oxide layer compared to the metal substrate would presumably lead to localised high stress concentration. This explains why for oxidized specimens surface crack initiation is promoted and the fatigue life is generally reduced, as reported by Cruchley et al. [25]. However, they also observed an improved fatigue life of oxidized specimens when the applied stress ranged between approximately 800 and $1000 \mathrm{MPa}$, which they attribute to plastic yielding of the $V^{\prime}$ denuded layer underneath the oxide. The residual stress analysis in the current study may provide another explanation, because it reveals the presence of a large compressive residual stress field. At a surface depth of approximately $1 \mu \mathrm{m}$, which corresponds to the $\gamma^{\prime}$ denuded layer just underneath the 
oxide layer, the residual stress is in fact close to $1000 \mathrm{MPa}$ in compression (see Figure 8). Therefore, it is clear that in order to correctly estimate the actual stress levels close to the surface during fatigue loading, the mechanical response of the oxide layer as well as the residual stress field should be considered.

Finally, a critical reflection should be made regarding the transferability of the results to the specific case of crack tip oxidation during dwell fatigue crack growth. A first consideration is that the mechanical properties of the oxide layer were evaluated at room temperature. At the operating temperature of turbine discs these properties are expected to change. For example, pure sintered $\mathrm{NiO}$ and $\mathrm{CoO}$ reportedly undergo a change in magnetic state above $250{ }^{\circ} \mathrm{C}$, which is coupled to a significant decrease in Poisson's ratio [42]. As the temperature increases, Young's modulus also decreases $[43,53]$. Furthermore, differences in thermal expansion coefficients between the substrate and the oxide phases will have an effect on the residual stress measured at room temperature, due to thermal cooling strains [12]. A second consideration is that oxidation on a surface plane and oxidation ahead of a crack tip can to some extent result in a different oxide layering sequence, due to the fact that in the latter case the matrix/oxide interfaces are aligned with the oxide growth direction, which provides easier diffusion paths [7]. Additionally, dwell fatigue cracks generally grow along grain boundaries, which also affects the diffusion of both oxygen and oxide-forming elements and consequently the oxide layer morphology [19]. A final important consideration is that, even though the oxide is under compressive residual stress, the geometric constraints in the case of an oxide intrusion at a crack tip can result in the presence of a balancing tensile stress ahead of the intrusion [11]. This 'anti-shielding' effect would explain the observation of accelerated dwell fatigue crack growth due to environmental degradation, i.e. SAGBO and crack tip oxidation $[2,3]$.

Due to the small scale of crack tip oxidation effects in nickel-based superalloys, experimental verification of the mechanical phenomena that govern crack growth is extremely challenging. Consequently, most studies generally rely on micromechanical modelling via computational methods. The current experimental results for surface oxidation may not be directly applicable to the case of crack tip oxidation, yet they do provide relevant insights into the morphology and room temperature mechanical properties of complex oxide layers in nickel-based superalloys. Furthermore, the 
results obtained in this study can be interpreted more directly to help improve our understanding of the effect of surface oxidation on fatigue crack initiation.

\section{Conclusions}

The crack initiation and propagation behaviour of nickel-based superalloys in turbine disc applications is governed by several interacting mechanical and environmental mechanisms. One important phenomenon is the formation of a layered oxide scale, which changes the local mechanical properties and stress field. In this study, the mechanical properties of a naturally grown oxide layer with submicron thickness on the surface of a nickel-based superalloy were evaluated, in order to understand better the mechanical behaviour of this complex layered structure. The key conclusions are summarised as follows:

- The outer surface of the oxide consisted of either nanocrystalline particles or oxide nano-whiskers of varying thickness and length, containing mainly Ti and $\mathrm{Cr}$. Below the surface, a relatively thick $\mathrm{Cr}_{2} \mathrm{O}_{3}$ layer was present, followed by a thin $\mathrm{Al}_{2} \mathrm{O}_{3}$ layer and finger-like $\mathrm{Al}_{2} \mathrm{O}_{3}$ intrusions into the underlying substrate. This layered structure showed some variability in both morphology and chemical composition.

- Using a combination of in situ mechanical microscopy techniques and FE modelling, the overall Poisson's ratio and Young's modulus of the oxide layer were determined to be respectively 0.29 and $259 \mathrm{GPa}$.

- Depth-resolved in-plane residual stress profiles were obtained by ring-core FIBDIC experiments and showed the presence of a large peak of compressive residual stress in the oxide layer. The magnitude of residual stress was found to depend on the local oxide thickness, and reached a maximum value of approximately $3000 \mathrm{MPa}$ in compression. Furthermore, buckling failure and spallation were observed at locations on the sample surface where the oxide had grown to a large thickness. To the author's knowledge, the depth-resolved residual stress in a native oxide layer with submicron thickness has never been evaluated experimentally before.

The results obtained in this study provide information that helps with understanding the effect of oxidation on fatigue crack initiation, and can help to improve the micromechanical modelling of crack tip oxidation during dwell fatigue crack growth. 


\section{Declarations of interest}

None.

\section{Data availability}

The raw/processed data required to reproduce these findings cannot be shared at this time as the data also forms part of an ongoing study.

\section{Acknowledgements}

The authors would like to acknowledge Dr. Sam Cruchley (University of Birmingham) for carrying out the oxidation experiment.

\section{References}

[1] R.C. Reed, The Superalloys fundamentals and applications, Cambridge University Press, 2006. doi:10.1017/CBO9780511541285.

[2] D.G. Leo Prakash, M.J. Walsh, D. Maclachlan, A.M. Korsunsky, Crack growth micro-mechanisms in the IN718 alloy under the combined influence of fatigue, creep and oxidation, Int. J. Fatigue. 31 (2009) 1966-1977. doi:10.1016/j.ijfatigue.2009.01.023.

[3] H.Y. Li, J.F. Sun, M.C. Hardy, H.E. Evans, S.J. Williams, T.J.A. Doel, P. Bowen, Effects of microstructure on high temperature dwell fatigue crack growth in a coarse grain PM nickel based superalloy, Acta Mater. 90 (2015) 355-369. doi:10.1016/j.actamat.2015.02.023.

[4] X. Liu, B. Kang, K.M. Chang, The effect of hold-time on fatigue crack growth behaviors of WASPALOY alloy at elevated temperature, Mater. Sci. Eng. A. 340 (2003) 8-14. doi:10.1016/S0921-5093(02)00074-6.

[5] Y.J. Oh, J.H. Hong, S.W. Nam, A model for creep-fatigue interaction in terms of crack-tip stress relaxation, Metall. Mater. Trans. A. 31 (2000) 1761-1775. doi:10.1007/s11661-998-0327-3.

[6] H. Ghonem, D. Zheng, Depth of intergranular oxygen diffusion during environment-dependent fatigue crack growth in alloy 718, Mater. Sci. Eng. A. 150 (1992) 151-160. doi:10.1016/0921-5093(92)90107-C. 
[7] A.A.N. Németh, D.J. Crudden, D.E.J. Armstrong, D.M. Collins, K. Li, A.J. Wilkinson, C.R.M. Grovenor, R.C. Reed, Environmentally-assisted grain boundary attack as a mechanism of embrittlement in a nickel-based superalloy, Acta Mater. 126 (2017) 361-371. doi:10.1016/j.actamat.2016.12.039.

[8] L. Viskari, S. Johansson, K. Stiller, Oxygen influenced intergranular crack propagation: analysing microstructure and chemistry in the crack tip region, Mater. High $\quad 28 \quad$ Temp. (2011) 336-341. doi:10.3184/096034011X13189599518971.

[9] S. Cruchley, H. Evans, M. Taylor, An overview of the oxidation of Ni-based superalloys for turbine disc applications: surface condition, applied load and mechanical performance, Mater. High Temp. 33 (2016) 465-475. doi:10.1080/09603409.2016.1171952.

[10] R. Jiang, D. Proprentner, M. Callisti, B. Shollock, X.T. Hu, Y.D. Song, P.A.S. Reed, Role of oxygen in enhanced fatigue cracking in a PM Ni-based superalloy: Stress assisted grain boundary oxidation or dynamic embrittlment?, Corros. Sci. 139 (2018) 141-154. doi:10.1016/j.corsci.2018.05.001.

[11] L. Cimbaro, A.P. Sutton, D.S. Balint, A.T. Paxton, M.C. Hardy, Embrittlement of an elasto-plastic medium by an inclusion, Int. J. Fract. (2019). doi:10.1007/s10704-019-00344-2.

[12] H.E. Evans, Stress effects in high temperature oxidation of metals, Int. Mater. Rev. 40 (1995) 1-40. doi:10.1179/imr.1995.40.1.1.

[13] A. Karabela, L.G. Zhao, B. Lin, J. Tong, M.C. Hardy, Oxygen diffusion and crack growth for a nickel-based superalloy under fatigue-oxidation conditions, Mater. Sci. Eng. A. 567 (2013) 46-57. doi:10.1016/j.msea.2012.12.088.

[14] E. Andrieu, R. Molins, H. Ghonem, A. Pineau, Intergranular crack tip oxidation mechanism in a nickel-based superalloy, Mater. Sci. Eng. A. 154 (1992) 21-28. doi:10.1016/0921-5093(92)90358-8.

[15] H. Ghonem, T. Nicholas, A. Pineau, Elevated Temperature Fatigue Crack Growth in Alloy 718-Part II: Effects of Environmental and Material Variables, Fatigue Fract. Eng. Mater. Struct. 16 (1993) 577-590. doi:10.1111/j.1460- 
2695.1993.tb00103.x.

[16] F. Abe, H. Araki, H. Yoshida, M. Okada, The role of aluminum and titanium on the oxidation process of a nickel-base superalloy in steam at $800 \mathrm{C}$, Oxid. Met. 27 (1987) 21-36. doi:10.1007/BF00656727.

[17] S. Cruchley, H.E. Evans, M.P. Taylor, M.C. Hardy, S. Stekovic, Chromia layer growth on a Ni-based superalloy: Sub-parabolic kinetics and the role of titanium, Corros. Sci. 75 (2013) 58-66. doi:10.1016/j.corsci.2013.05.016.

[18] R. Jiang, P.A.S. Reed, Critical Assessment 21: oxygen-assisted fatigue crack propagation in turbine disc superalloys, Mater. Sci. Technol. 32 (2016) 401-406. doi:10.1080/02670836.2016.1148227.

[19] H.S. Kitaguchi, H.Y. Li, H.E. Evans, R.G. Ding, I.P. Jones, G. Baxter, P. Bowen, Oxidation ahead of a crack tip in an advanced Ni-based superalloy, Acta Mater. 61 (2013) 1968-1981. doi:10.1016/j.actamat.2012.12.017.

[20] T.D. Reynolds, M.P. Taylor, D.J. Child, H.E. Evans, The effect of elevated air pressure on the oxidation properties of the nickel-based superalloy, RR1000, at $650^{\circ} \mathrm{C}$ with different surface modifications, Mater. High Temp. 35 (2018) 130140. doi:10.1080/09603409.2017.1389132.

[21] K.S. Chan, A Grain Boundary Fracture Model for Predicting Dynamic Embrittlement and Oxidation-Induced Cracking in Superalloys, Metall. Mater. Trans. A. 46 (2015) 2491-2505. doi:10.1007/s11661-015-2860-1.

[22] K.S. Chan, Time-Dependent Crack Growth Thresholds of Ni-Base Superalloys, Metall. Mater. Trans. A. 45 (2014) 3454-3466. doi:10.1007/s11661-014-22718.

[23] X. Ma, Z. Duan, H. Shi, R. Murai, E. Yanagisawa, Fatigue and fracture behavior of nickel-based superalloy Inconel 718 up to the very high cycle regime, J. Zhejiang Univ. A. 11 (2010) 727-737. doi:10.1631/jzus.A1000171.

[24] J.C. Stinville, W.C. Lenthe, M.P. Echlin, P.G. Callahan, D. Texier, T.M. Pollock, Microstructural statistics for fatigue crack initiation in polycrystalline nickel-base superalloys, Int. J. Fract. 208 (2017) 221-240. doi:10.1007/s10704-017-0241-z.

[25] S. Cruchley, H.Y. Li, H.E. Evans, P. Bowen, D.J. Child, M.C. Hardy, The role of 
oxidation damage in fatigue crack initiation of an advanced Ni-based superalloy, Int. J. Fatigue. 81 (2015) 265-274. doi:10.1016/j.ijfatigue.2015.08.016.

[26] S.J. Hessel, W. Voice, A.W. James, S.A. Blackham, C.J. Small, M.R. Winstone, Nickel Alloy for Turbine Engine Component, US Patent 6132527, 2000.

[27] M. Sebastiani, C. Eberl, E. Bemporad, A.M. Korsunsky, W.D. Nix, F. Carassiti, Focused ion beam four-slot milling for Poisson's ratio and residual stress evaluation at the micron scale, Surf. Coatings Technol. 251 (2014) 151-161. doi:10.1016/j.surfcoat.2014.04.019.

[28] M. Senn, Digital Image Correlation and Tracking, MathWorks. (2016). https://uk.mathworks.com/matlabcentral/fileexchange/50994-digital-imagecorrelation-and-tracking (accessed April 3, 2019).

[29] J. Everaerts, C. Papadaki, W. Li, A.M. Korsunsky, Evaluation of single crystal elastic stiffness coefficients of a nickel-based superalloy by electron backscatter diffraction and nanoindentation, J. Mech. Phys. Solids. 131 (2019) 303-312. doi:10.1016/j.jmps.2019.07.011.

[30] A.M. Korsunsky, M. Sebastiani, E. Bemporad, Focused ion beam ring drilling for residual stress evaluation, Mater. Lett. 63 (2009) 1961-1963. doi:10.1016/j.matlet.2009.06.020.

[31] A.M. Korsunsky, E. Salvati, A.G.J. Lunt, T. Sui, M.Z. Mughal, R. Daniel, J. Keckes, E. Bemporad, M. Sebastiani, Nanoscale residual stress depth profiling by Focused Ion Beam milling and eigenstrain analysis, Mater. Des. 145 (2018) 55-64. doi:10.1016/j.matdes.2018.02.044.

[32] E. Salvati, L. Romano-Brandt, M.Z. Mughal, M. Sebastiani, A.M. Korsunsky, Generalised residual stress depth profiling at the nanoscale using focused ion beam milling, J. Mech. Phys. Solids. 125 (2019) 488-501. doi:10.1016/j.jmps.2019.01.007.

[33] A.J.G. Lunt, A.M. Korsunsky, A review of micro-scale focused ion beam milling and digital image correlation analysis for residual stress evaluation and error estimation, Surf. Coatings Technol. 283 (2015) 373-388. doi:10.1016/J.SURFCOAT.2015.10.049. 
[34] E. Salvati, T. Sui, A.M. Korsunsky, Uncertainty quantification of residual stress evaluation by the FIB-DIC ring-core method due to elastic anisotropy effects, Int. J. Solids Struct. 87 (2016) 61-69. doi:10.1016/j.ijsolstr.2016.02.031.

[35] S. Cruchley, J.F. Sun, M.P. Taylor, H.E. Evans, P. Bowen, J. Sumner, J.R. Nicholls, N.J. Simms, B.A. Shollock, R.J. Chater, B.J. Foss, M.C. Hardy, S. Stekovic, Cautionary note on use of focused ion beam sectioning as technique for characterising oxidation damage in Ni based superalloys, Mater. High Temp. 31 (2014) 27-33. doi:10.1179/0960340913Z.0000000004.

[36] M.G. Mueller, G. Žagar, A. Mortensen, In-situ strength of individual silicon particles within an aluminium casting alloy, Acta Mater. 143 (2018) 67-76. doi:10.1016/j.actamat.2017.09.058.

[37] X. Pang, K. Gao, A.A. Volinsky, Microstructure and mechanical properties of chromium oxide coatings, J. Mater. Res. 22 (2007) 3531-3537. doi:10.1557/jmr.2007.0445.

[38] X. Pang, K. Gao, H. Yang, L. Qiao, Y. Wang, A.A. Volinsky, Interfacial Microstructure of Chromium Oxide Coatings, Adv. Eng. Mater. 9 (2007) 594599. doi:10.1002/adem.200700057.

[39] S. Osgerby, K. Berriche-Bouhanek, H.E. Evans, Tensile cracking of a chromia layer on a stainless steel during thermal cycling with hold periods, Mater. Sci. Eng. A. 412 (2005) 182-190. doi:10.1016/j.msea.2005.08.193.

[40] D.W. Richerson, W.E. Lee, Modern Ceramic Engineering: Properties, Processing, and Use in Design, 2nd ed., CRC Press, 1992.

[41] J.F. Shackelford, W. Alexander, CRC Materials Science and Engineering Handbook, 3rd ed., CRC Press, 2000.

[42] M.R. Notis, R.M. Spriggs, W.C. Hahn Jr., Elastic moduli of pressure-sintered nickel oxide, J. Geophys. Res. 76 (1971) 7052-7061. doi:10.1029/JB076i029p07052.

[43] L.A. Yevtuschenko, H.A. Levitin, Anomalies in the modulus of elasticity of the antiferromagnetic materials Mno, CoO, and Cr2O3, Met. Met. 12 (1961) 139140. 
[44] A.M. Korsunsky, E. Salvati, A.G.J. Lunt, T. Sui, M.Z. Mughal, R. Daniel, J. Keckes, E. Bemporad, M. Sebastiani, Nanoscale residual stress depth profiling by Focused Ion Beam milling and eigenstrain analysis, Mater. Des. 145 (2018) 55-64. doi:10.1016/j.matdes.2018.02.044.

[45] Tortorelli, P. F., Mechanical properties of chromia scales, J. Phys. IV Fr. 03 (1993) C9-943-C9-949. doi:10.1051/jp4:1993997.

[46] W.W. Gerberich, W.M. Mook, C.B. Carter, R. Ballarini, A crack extension force correlation for hard materials, Int. J. Fract. 148 (2007) 109-114. doi:10.1007/s10704-008-9177-7.

[47] Luo, Yan-Ting, Chen, Zhi-Qian, Elasticity and Anisotropy of Titanium Oxide TixOy, MATEC Web Conf. $67 \quad$ (2016) 6014. doi:10.1051/matecconf/20166706014.

[48] A.H.S. Iyer, K. Stiller, M.H. Colliander, Room temperature plasticity in thermally grown sub-micron oxide scales revealed by micro-cantilever bending, Scr. Mater. 144 (2018) 9-12. doi:10.1016/j.scriptamat.2017.09.036.

[49] N. Pilling, R.J. Bedworth, The Oxidation of Metals at High Temperatures, J. Inst. Met. 29 (1923) 529-591.

[50] C. Xu, W. Gao, Pilling-Bedworth ratio for oxidation of alloys, Mater. Res. Innov. 3 (2000) 231-235. doi:10.1007/s100190050008.

[51] M. Preuss, J. Quinta da Fonseca, B. Grant, E. Knoche, R. Moat, M. Daymond, The effect of $\mathrm{Y}^{\prime}$ particle size on the deformation mechanism in an advanced polycrystalline nickel-base superalloy, in: Superalloys, TMS, Champion, Pennsylvania, 2008: pp. 405-414.

[52] J. Everaerts, E. Salvati, A.M. Korsunsky, Nanoscale Depth Profiling of Residual Stresses Due to Fine Surface Finishing, Adv. Mater. Interfaces. 0 (n.d.) 1900947. doi:10.1002/admi.201900947.

[53] I.A. Menzies, K.N. Strafford, Observations on the mechanical properties of nickel oxide scales, J. Mater. Sci. 2 (1967) 358-364. 